\title{
Gestão da educação municipal nos sistemas e redes de ensino/educação tocantinenses: desafios na garantia do direito educacional no período da pandemia
}

\footnotetext{
(iD) Rute Soares Rodrigues ${ }^{1}$, (D) Idemar Vizolli ${ }^{2}$, (D) Maria Solange Rodrigues de Sousa ${ }^{3}$, (D) Meire Lúcia Andrade da Silva ${ }^{4}$ 1, 2, 3, 4 Universidade Federal do Tocantins - UFT. Programa de Pós-Graduação em Educação. Avenida NS15 ALC NO 14. Palmas - TO. Brasil.
}

Autor para correspondência/Author for correspondence: rutte.sr@gmail.com

\begin{abstract}
RESUMO. Este artigo trata da gestão da educação municipal dos/nos sistemas e redes de ensino/educação tocantinenses em relação à garantia do direito educacional no período da pandemia da Covid-19. Objetiva apreender os desafios e dilemas enfrentados pelas Secretarias Municipais de Ensino/Educação em municípios tocantinenses no período pandêmico, mais precisamente sobre o ensino remoto, híbrido e/ou com o uso das tecnologias digitais de informação e comunicação (TDIC) como forma de garantir o direito educacional instituído por lei. Tratase de uma pesquisa bibliográfica-documental, que aborda sobre a gestão da educação fundamentado nas normas educacionais das esferas estadual e federal, a partir de uma pesquisa de campo desenvolvida pela União Nacional dos Dirigentes Municipais de Educação (UNDIME). O estudo apresenta resultados do diagnóstico situacional dos municípios por ocasião do início da pandemia em 2020 e evidencia: dificuldades das secretarias municipais de educação, implicações do ensino não presencial, plano de retomada das aulas presenciais para os anos letivos 2020 e 2021. O panorama da realidade educacional no Estado do Tocantins carece de maiores investimentos em tecnologia e conectividade às escolas; formação dos profissionais da educação; melhorias na infraestrutura das unidades educacionais a fim de que se cumpra o direito à educação.
\end{abstract}

Palavras-chave: ensino remoto e híbrido, suspensão de aulas, tecnologias, pandemia. 


\title{
Municipal education management in the tocantinense education systems and networks: challenges in ensuring the right to education in the pandemic period
}

\begin{abstract}
This article focuses on the management of municipal education in the system and educational networks of the state of Tocantins, regarding the guarantee of the right to education in the period of the Covid-19 pandemic. It aims to understand the challenges and dilemmas faced by the Secretaries of Education in municipalities of Tocantins in the pandemic period, more precisely about remote, hybrid education and the use of digital information and communication technologies (ICT) as a way to ensure the educational rights established by law. This is bibliographic-documentary research that deals with the management of education grounded in the regulations of the state and federal spheres and based on field research developed by the National Union of Municipal Education Directors (UNDIME). The study presents the results of the situational diagnosis of the municipalities at the start of the pandemic in 2020 and evidences: the difficulties of the Municipal Secretaries of Education, the implications of the non-face-to-face teaching, the plan to resume face-to-face classes for the 2020 and 2021 school years. Also, the panorama of the educational reality in the state of Tocantins lacks of major investments in technology and connectivity in the schools; better training for education professionals and improvements in the infrastructure of educational units in order to fulfill the right to education.
\end{abstract}

Keywords: remote and hybrid teaching, abeyance of classes, technologies, pandemic. 


\section{La gestión municipal de la educación en los sistemas y redes de enseñanza tocantinense: desafíos para garantizar el derecho a la educación durante el período de pandemia}

RESUMEN. Este artículo trata de la gestión de la educación municipal en los sistemas y redes de enseñanza/educación en Tocantins, en relación con la garantía del derecho educacional en el período de la pandemia de Covid-19. Tiene como objetivo aprehender los desafíos y dilemas que enfrentan los Secretarías Municipales de Enseñanza/Educación de los municipios de Tocantins en el período pandémico, más precisamente sobre la educación a distancia, híbrida y/o con el uso de las tecnologías digitales de información y comunicación (TDIC) como forma de garantizar el derecho educativo establecido por la ley. Se trata de una investigación bibliográfica-documental, que aborda la gestión de la educación con base en las normas educativas de las esferas estatal y federal, a partir de una investigación de campo desarrollada por la Unión Nacional de Directores Municipales de Educación (UNDIME). El estudio presenta los resultados del diagnóstico situacional de los municipios con motivo del inicio de la pandemia en 2020 y destaca: las dificultades de las Secretarías Municipales de Educación, las implicaciones de la enseñanza no presencial y el plan de reanudación de las clases presenciales para los años escolares 2020 y 2021. El panorama de la realidad educativa en el Estado de Tocantins, carece de inversiones mayores en tecnología y conectividad en las escuelas; de la formación de los profesionales de la educación y mejoras en la infraestructura de las unidades educativas para cumplir con el derecho a la educación.

Palabras clave: enseñanza a distancia e híbrida, suspensión de clases, tecnologías educativas, pandemia. 


\section{Introdução}

A pandemia da Covid-19 provocou impactos relevantes no modo de vida em todo o mundo, isso porque a gravidade da doença impôs a necessidade de alterar a rotina, repensar e reorganizar o convívio social. A Organização Mundial de Saúde (OMS), após declarar situação de emergência de saúde pública internacional, apresentou como uma das medidas de combate à propagação da doença, o distanciamento social (OPAS/OMS/2020), o que causou o fechamento de escolas e a suspensão das aulas presenciais na maioria dos países.

No Estado do Tocantins, a partir das determinações da OMS, foram publicados vários decretos para orientar os municípios sobre a proliferação do contágio da Covid19. Desde março de 2020 até 11 de agosto de 2021, os dados oficiais explicitam o contexto pandêmico ${ }^{\mathrm{i}}$ evidenciando: 213.478 casos confirmados; 9.872 casos ativos; 200.021 casos recuperados e 3.585 óbitos.

Em 2020, o Decreto Estadual $\mathrm{n}^{\circ}$ 6.065, de 13 de março de 2020, determinou a suspensão das aulas presenciais em todos os sistemas e redes de ensino do território tocantinense, estabelecendo que os Conselhos de Educação adotassem medidas para garantir o vínculo educacional com os estudantes e seus familiares. Na época, tudo parecia ser uma ação rápida e passageira, porém, a situação se agravou e as aulas presenciais continuaram suspensas, sendo autorizado o retorno de forma gradual, por meio do Decreto Estadual $n^{\circ}$ 6.257, de 14 de maio de 2021. A retomada das aulas ficou sob a responsabilidade do poder executivo de cada município, a quem caberia analisar o cenário de transmissão do vírus e determinar o dia de retorno das atividades, mantendo-se o devido cumprimento de protocolos de saúde.

Com isso, a escola, onde os estudantes passam grande parte do tempo de suas vidas, também precisou reinventar sua forma de funcionar para continuidade da oferta do processo educacional, de modo a garantir o direito à educação para todos, portanto, mesmo em situações de excepcionalidade, deve ser garantida. Para Furtado (2021), a pandemia da Covid-19 trouxe uma disrupção no processo educacional, o que levou os sistemas e as redes de ensino a adotarem novas regras e novo formato de ensinar, o que deu origem ao modelo remoto e híbrido, mediado, ou não, por tecnologias digitais.

Por se tratar de uma situação nova e desafiadora, os municípios tiveram muitas dificuldades em organizar o atendimento educacional de forma não presencial para 
os estudantes, inicialmente por falta de colaboração/orientação dos entes federados. Em outras palavras, houve demora da parte do Ministério da Educação (MEC) - via Conselho Nacional de Educação (CNE) e Conselho Estadual de Educação do Tocantins (CEE/TO) - em publicar as normas complementares para atender a excepcionalidade em questão. Com isto,

Inúmeras são as dúvidas das equipes escolares diante da falta de diretrizes dos órgãos de Educação Nacional no tocante à oferta de educação não presencial, seja na modalidade de educação à distância ou qualquer outra forma de ensino remoto voltado à educação básica (educação infantil, ensino fundamental e ensino médio). Há distinção nesses modelos de educação e a regulamentação do processo a ser adotado pelo sistema de ensino é indispensável. (Oliveira $\&$ Peres, 2020, p. 1 grifo nosso).

A esse respeito, Bazzo (2020) afirma que, pressionados pelas incertezas e pelos muitos questionamentos de pais, professores e estudantes, principalmente os das séries finais do Ensino Fundamental, entre outras tensões, levou os secretários estaduais e municipais de educação a cobrarem (em vão) do MEC, parcerias coordenadas para a oferta do ensino remoto e reorganização do calendário escolar. "Limitou-se o referido colegiado a emitir o Parecer CNE/CP $n^{\circ}$ 5/2020, aprovado em 28 de abril e homologado em
29 de maio de 2020" (BAZZO, 2020, p. 38).

Para orientar as redes e sistemas de ensino, o CNE emitiu o parecer $\mathrm{n}^{\circ} 05$ e $11 / 2020$, que possibilitou a realização de aulas ou atividades pedagógicas não presenciais mediadas ou não por tecnologias digitais de informação e comunicação, estabelecendo assim, o formato de ensino remoto. O parecer de caráter apenas orientador,

... não assumia a coordenação das iniciativas sugeridas, informando, isso sim, que a competência para definir a reorganização dos calendários e a realização de atividades pedagógicas não presenciais seria dos próprios sistemas de ensino.

... estava confirmada, portanto, a possibilidade da fragmentação de ações e de respostas. Não haveria uma diretriz central e unificadora. Cada estado, cada município, cada rede, de acordo com suas realidades ou conveniências, decidiriam como tratar do imenso desafio que o setor educacional no país estava enfrentando, sem nenhuma garantia de que o período de excepcionalidade seria breve. E, o mais grave, sem saber de onde viriam os recursos para custear as ações que se mostrassem mais adequadas à situação. $O$ dono do cofre nacional não se sentia comprometido com o lockdown. Não seria ele a custeá-lo, arrisco dizer. (Bazzo, 2020, p. 38-39, grifo do nosso).

Conforme explica Grossi (2020), o ensino remoto não é Educação a Distância (EaD) a qual que tem sua regulamentação específica, mas é uma estratégia 
pedagógica que além de ter professores e alunos como atores do processo educacional, a participação da família é bem mais ativa e necessária do que no presencial. Desse modo, o ensino remoto se tornou uma opção para a continuidade da oferta do ensino, uma vez que a educação não pode esperar, tendo em vista que o afastamento social e as paralisações podem gerar efeitos nefastos na aprendizagem.

No contexto da pandemia, o termo "ensino remoto" se popularizou.

O isolamento social, necessário para impedir a expansão da infecção por Covid-19, fez com que as atividades presenciais nas instituições educacionais deixassem de ser o "normal". Por isso, as instituições educacionais passaram a utilizar de forma generalizada estratégias de EaD. O problema é que, para manter as atividades regulares funcionando na "nova normalidade" criada pela pandemia de Covid-19, muitas instituições, especialmente do setor privado, começaram a utilizar estratégias que violavam a legislação vigente utilizando um eufemismo: o ensino remoto. (Grossi, 2020, p. 38).

Toda essa situação permite que se reflita sobre o ensino remoto como solução alternativa para esse contexto, mas com muitas interrogações sobre se essa modalidade de ensino, de fato suprirá as necessidades estabelecidas nos currículos; se estudantes e professores vão se adaptar; quais os impactos no processo de ensino e aprendizagens; e como ficarão as relações entre escolas e famílias. Enfim, muitos são os desafios e dilemas que perpassam essa modalidade de ensino, os quais não possuem respostas imediatas e necessitam ser cuidadosamente analisados.

Assim, o objetivo deste estudo é apreender os desafios e dilemas enfrentados pelas Secretarias Municipais de Ensino/Educação em municípios tocantinenses, no período da pandemia, por meio do ensino remoto, híbrido e/ou com o uso das tecnologias digitais de informação e comunicação (TDIC), como forma de garantir o direito educacional instituído por lei. Pauta-se em pesquisa exploratória de revisão bibliográfica (Lima \& Mioto, 2007) e documental, envolvendo as normas do CNE (Brasil, 2020; 2020a; 2020b; 2020c; 2020d;), do CEE/TO (Tocantins, 2020a; 2020b; 2020c; 2020d; 2020e; 2020f; 2020g) e de campo, a partir das pesquisas realizadas pela União Nacional de Dirigentes Municipais de Educação (UNDIME, 2020; 2021).

Para Lima e Mioto (2007, p. 41), a forma de se realizar uma pesquisa bibliográfica é a leitura, “... pois, é através dela que se pode identificar as informações e os dados contidos no material selecionado, bem como verificar as relações existentes entre eles, de modo a analisar a sua consistência". A pesquisa 
documental, para Gil (2008), vale-se de materiais que não receberam ainda tratamento analítico, além de analisar os documentos de "primeira mão" documentos de arquivos e instituições etc. Existem, também, aqueles que já foram processados, mas podem receber outras interpretações, como relatórios de empresas, tabelas etc.

Gil (2008) considera que o estudo de campo procura o aprofundamento de uma realidade específica. É realizado por meio de questionário semiestruturado e/ou observação direta das atividades do grupo estudado e de entrevistas com informantes para captar as explicações e interpretações que ocorrem naquela realidade.

\section{Gestão da educação municipal e o direito à educação}

A Constituição Federal de 1988, em seu art. 208, § $1^{\circ}$ preconiza que a Educação Básica é direito público subjetivo, devendo ser garantida a todos os cidadãos. Para Cury (2002), do dever de Estado nascem obrigações que devem ser respeitadas, tanto da parte de quem tem a responsabilidade de efetivá-las, como os poderes constituídos; quanto da parte de outros sujeitos implicados nessas obrigações, que devem, também, colaborar com elas.
O artigo 206 da Constituição de 1988 garante que o ensino será ministrado com base nos seguintes princípios:

I - igualdade de condições para o acesso e permanência na escola; II - liberdade de aprender, ensinar, pesquisar e divulgar o pensamento, a arte e o saber;

III - pluralismo de ideias e de concepções pedagógicas ...;

IV - gratuidade do ensino público em estabelecimentos oficiais;

V - valorização dos profissionais da educação escolar, garantidos, na forma da lei, planos de carreira, com ingresso exclusivamente por concurso público de provas e títulos, aos das redes públicas;

VI - gestão democrática do ensino público, na forma da lei;

VII - garantia de padrão de qualidade;

VIII - piso salarial profissional nacional para os profissionais da educação escolar pública, nos termos de lei federal. (Brasil, 1988).

Diante da garantia constitucional, esses direitos educacionais não podem, portanto, serem interrompidos. O Plano Nacional de Educação (PNE) 2014-2024 também determinou em seu artigo $2^{\circ}$ as seguintes diretrizes: ... II - universalização do atendimento escolar; III - superação das desigualdades educacionais, com ênfase na promoção da cidadania e na erradicação de todas as formas de discriminação; IV melhoria da qualidade da educação ... (Brasil, 2014).

Assim, mesmo com as restrições impostas pela pandemia da Covid-19, tornou-se necessário definir novas formas 
de atuação e metodologias para as aulas e atividades não presenciais. Embora o ensino remoto seja uma opção para o contexto da pandemia, possibilitando a oferta educacional, de fato representou um grande desafio para as redes e sistemas de ensino, sobretudo porque as secretarias de educação, professores e demais profissionais da educação se viram em dificuldades para implementar o trabalho não presencial. Os poucos recursos tecnológicos, ou até mesmo a ausência deles, além da falta de conectividade com a Internet dificulta ainda mais esse formato de ensino.

Essa realidade impõe a necessidade de potencialização dos processos de aprendizagens na perspectiva da garantia do direito à educação, o que reafirma a urgência de se trabalhar as questões relativas ao reconhecimento e à valorização das diferenças culturais nos contextos escolares (Candau, 2012).

Compreende-se que o ensino, mesmo de forma remota, tem sido considerado essencial à manutenção do vínculo dos estudantes com a escola, contribuindo com a redução das taxas de abandono e evasão escolar, bem como para assegurar conteúdos pedagógicos, de modo a alcançar os alunos e a evitar que as desigualdades educacionais existentes nas redes e sistemas de ensino/educação se ampliem.

Este processo tem sido denominado ensino remoto, no qual a equipe escolar faz uma adaptação do modelo presencial de aprendizagem, com a utilização dos recursos tecnológicos disponíveis, sempre que possível, para o envio e devolutiva de atividades escolares aos educandos e familiares, como forma de manutenção do processo de aprendizagem de maneira não presencial.

... a alternativa vivenciada pelos sistemas de ensino, imediatamente após a suspensão de aulas, num esforço conjunto entre professores, gestores e família, é a utilização de recursos de tecnologia e informação (comunidades no Facebook, WhatsApp, You Tube, etc.) para o envio de atividades escolares aos educandos no formato de vídeos gravados no celular, indicação de canais educativos, lives nas redes sociais, dentre outras, como também a disponibilização de recursos já existentes (materiais impressos/xerocópias, entrega de livros didáticos), especialmente àqueles que não dispõem de computadores, tablets ou celulares e nem mesmo acesso à internet. (Oliveira \& Peres, 2020, p. 4).

O desafio das redes e sistemas de ensino/educação tem sido grande neste contexto da pandemia da Covid-19, isto porque impôs uma nova rotina, com alternativas diferenciadas, adaptações rápidas e resiliência para que o processo educacional ocorra e consiga atender as realidades dos estudantes, docentes e famílias, conforme pontuam Barreto et al. (2020). 
$\mathrm{O}$ ensino remoto, como explica Arruda (2020), refere-se à realização de aulas em tempo real, ou seja, aulas síncronas em que há interação entre professores e estudantes, online, bem como aulas gravadas ou assíncronas, de forma atemporal, em ambientes virtuais. Por sua vez, o formato híbrido, que combina aulas ou atividades presenciais e online/remota dentro ou fora do espaço escolar, também é uma alternativa para que as aulas aconteçam com o mínimo de segurança, mantendo o distanciamento social, realidade ainda ausente em muitos municípios tocantinenses.

O ensino híbrido, modelo que combina atividades online e presencial, também tem sido uma opção para a oferta educacional. Para Bacich (2018, p. 6), “o ensino híbrido é uma mistura metodológica que impacta a ação do professor em situações de ensino e a ação dos estudantes em situações de aprendizagem". Em relação ao termo, Bacich (2016) explica que ele está fundamentado na concepção de que há variadas formas de aprender, bem como na compreensão de que a aprendizagem é um processo contínuo. Desse modo, o ensino híbrido tem sido implementado nesse contexto pandêmico, combinando a modalidade presencial e online ou remota, com uso, ou não, de tecnologia digital, agregando diferentes espaços que possibilitam o ensino aprendizagem.

Em razão da pandemia, as tecnologias digitais e de comunicação como Internet, computadores, as mídias sociais Whatsapp, e-mail, Instagram, Facebook têm sido utilizadas para a oferta educacional, visando garantir o direito à educação e, consequentemente, manter o distanciamento social e a segurança da saúde. Nesse sentido, compreende-se que tais tecnologias se constituem em ferramentas importantes a serem adotadas nesse contexto pandêmico, o qual exige maior flexibilização, tendo em vista os protocolos sanitários necessários de serem seguidos para o combate à Covid-19.

Observa-se que a pandemia agravou, ainda mais os problemas educacionais no Tocantins. Como pontua Lagares (2020, p. 4), o cenário da educação é preocupante no Estado,

... fervilham questões que têm sido discutidas historicamente pelo campo democrático popular que, ao nosso ver, são centrais e podem gerar efeitos mais perversos para uns que para outros. Dentre elas, talvez a maior diga respeito às fortes desigualdades educacionais [e sociais], estando a classe popular 'jogada a própria sorte' no que diz respeito ao direito à educação. O mais provável é, então, que o distanciamento temporal em relação à escola fortaleça tais desigualdades entre os alunos das diferentes classes sociais ou até eleve as taxas de abandono e evasão da classe popular. 
Segundo Nóvoa (1997), uma mudança educacional depende dos professores, de sua formação e também das práticas pedagógicas. Essa inovação pode acontecer paralelamente à introdução de tecnologias digitais integradas ao currículo, sobretudo, em uma época na qual dispositivos e softwares são, cada vez mais, interativos e funcionais.

\section{Dilemas e desafios das Secretarias Municipais de Educação na oferta de atividades educacionais não presenciais}

No Estado do Tocantins, muitos são os desafios advindos da Covid-19, de acordo com quatro pesquisas que foram realizadas pela União dos Dirigentes Municipais de Educação (Undime) e Conselho Nacional de Secretários Estaduais de Educação (Consed) com apoio do Centro de Inovação para a Educação Brasileira (CIEB), Fundação Itaú de Educação e Cultura e outros parceiros do terceiro setor.

A pesquisa realizada pela Undime, Consed, Cieb e Itaú Social foi desenvolvida no período de 27 de abril a 04 de maio de 2020 e contou com a participação de 100\% dos municípios tocantinenses. $\mathrm{O}$ estudo intitulado: "Desafios das Secretarias Municipais de Educação na oferta de atividades educacionais não presenciais" investigou as seguintes categorias: a) determinação dos governos em relação à pandemia; b) estratégias de aprendizagem remota adotadas; c) planejamento para monitoramento das atividades; d) principais desafios de implementação do ensino remoto e frentes em que as secretarias de educação mais precisam de apoio.

Para análise e melhor compreensão das respostas, a pesquisa considerou os dados da PNAD/IBGE (Brasil, 2020) mostrando que, no Estado do Tocantins, $58 \%$ dos alunos das redes públicas pertencem a famílias de baixa renda, que recebem até $1 / 2$ salário mínimo per capita. Esse dado revela que é mais complicado para uma grande quantidade de famílias e estudantes enfrentarem a realidade da pandemia, tendo em vista que se encontram em situação de vulnerabilidade socioeconômica.

Em âmbito nacional, a pesquisa Undime, Itaú e Unicef (2020), coletou dados de $70 \%$ das redes e sistemas municipais do país, o equivalente a mais de 14 milhões de matrículas da educação básica, abarcando um percentual robusto, que possibilita maior entendimento da situação relativa à suspensão presencial das aulas em razão da Covid-19. No Tocantins, o estudo em questão teve uma precisão de $100 \%$, visto que todos os municípios 
responderam à pesquisa, revelando os seguintes dados:

$\checkmark \quad 77 \%$ dos alunos das redes públicas do Tocantins têm acesso à internet, mas, desse total, apenas $25 \%$ têm internet e computador em casa.

$\checkmark \quad 51,8 \%$ têm internet apenas pelo celular.

$\checkmark \quad$ Para minimizar a suspensão das aulas, houve adiantamento de férias e recesso dos professores.

$\checkmark \quad$ Desde a suspensão das aulas, no Estado, ocorrida a partir de 18 de abril, por meio do Decreto Estadual até 04 de maio de 2020, quando a pesquisa foi realizada, $89 \%$ das redes suspenderam as aulas, mas não adotaram medidas de continuidade e 138, ou seja, 99,2\% dos municípios não tinham nenhuma normativa implementada.

Das poucas redes e sistemas de ensino que, nesse período, adotaram o ensino remoto, 12 disseram que utilizam material impresso como estratégia de aprendizagem não presencial, 4 usam conteúdos digitais e 4 deram autonomia para as escolas e 5 disseram, ainda, estarem realizando planejamento.

$\checkmark \quad$ Os principais desafios para implementar o ensino remoto foram a falta de equipamentos de professores e alunos, a dificuldade dos professores com as plataformas digitais e a baixa conectividade por parte de professores e alunos.

$\checkmark$ As maiores necessidades que as secretarias disseram precisar de apoio com o ensino remoto foi quanto às orientações às famílias e às normativas sobre a suspensão das aulas.

Observa-se que, no início da pandemia, os dados revelaram serem grandes os desafios para a continuidade das aulas de forma remota porque faltava acesso a computadores com Internet, uma vez que a maioria dos estudantes dispõe de Internet apenas no celular, podendo dificultar o processo de aprendizagem. A pesquisa também mostrou que as redes ou sistemas não sabiam como proceder diante da suspensão das aulas presenciais e como continuar garantindo a educação, como direito de todos.

O resultado da mencionada pesquisa, que tratou de compreender o cenário inicial da suspensão das aulas na pandemia, evidencia uma realidade difícil para as redes ou sistemas de ensino/educação quanto à continuidade da oferta da educação básica no Estado do Tocantins. Dificuldades essas relacionadas as condições tecnológicas, ao acesso a internet, dificuldades dos professores com o manuseio das TICs e as lacunas relativas as normas sobre como agir com as famílias, tendo em vista as mudanças abruptas ocorridas no processo de ensino e aprendizagem.

Observa-se que os docentes tiveram que fazer mudanças significativas para ministrar suas aulas. Como apontam Vieira e Seco (2020, p. 1024),

os professores tiveram que adaptar, de um momento para outro, suas práticas pedagógicas e planos de ensino a um modelo de ensino a distância, em muitos casos, sem os conhecimentos e competências digitais essenciais para promover 
uma aprendizagem de qualidade ... as instituições educacionais e os professores foram forçados a adotar práticas de ensino remoto de emergência que muito diferenciam das práticas de uma educação online de qualidade.

Todo esse cenário que a pesquisa revelou mostra incertezas quanto ao processo educacional no período da pandemia.

Esta mudança súbita nos processos educacionais tem gerado muitas incertezas por parte dos gestores das escolas, professores, estudantes, pais e comunidade científica acerca da eficácia do ensino não presencial, mediado pelas tecnologias digitais quanto à aprendizagem, principalmente na educação básica e secundária, quando comparado ao ensino presencial a que todos estavam acostumados. (Vieira \& Seco, 2020, p. 1015).

A pesquisa evidenciou fragilidades no tocante ao uso das tecnologias da informação e comunicação no processo educacional, mesmo diante do avanço tecnológico e da conectividade da internet banda larga de alta velocidade disponível em grande parte no país. O Plano Nacional de Educação define que uma das estratégias para alcançar a meta 7 de fomentar a qualidade da educação básica, com melhoria do fluxo escolar e da aprendizagem, é a universalização da Internet. A estratégia 7.15 prevê:
... universalizar, até o quinto ano de vigência deste PNE, o acesso à rede mundial de computadores em banda larga de alta velocidade e triplicar, até o final da década, a relação computador/aluno (a) nas escolas da rede pública de educação básica, promovendo a utilização pedagógica das tecnologias da informação e da comunicação. (Brasil, 2014).

Nota-se que, mesmo previsto em lei, a universalização da internet de alta velocidade, até o momento não é uma realidade para todas as escolas públicas brasileiras e sua utilização com fins pedagógicos ainda deixa a desejar.

Diante desse contexto, é notório que com o ensino remoto e online, faz-se necessário o acesso à Internet e computadores para a realização de aulas síncronas ou assíncronas por meio de alguma plataforma digital.

A segunda pesquisa, Undime, Itaú e Unicef (2020), realizada no período de 7 a 18 de agosto de 2020 junto aos municípios tocantinenses, teve como foco as ações das secretarias municipais de educação, durante a pandemia da Covid-19, revelando que:

92\% das redes e sistemas de ensino/educação estão realizando atividades não presenciais com seus alunos.

$\checkmark \quad 90 \%$ utilizavam material impressos.

$\checkmark \quad 64 \%$ usaram videoaulas gravadas.

$\checkmark \quad 12,4 \%$ disseram usar plataformas digitais para as aulas.

$6,5 \%$ realizavam videoaulas 
online ao vivo.

$\checkmark \quad 1$ município adotou aulas por meio da televisão.

$\checkmark \quad 61,3 \%$ das redes e sistemas adotaram pelo menos uma combinação de estratégia online, via internet, com uma estratégia, sem uso de internet.

$\checkmark \quad 30 \%$ usaram apenas estratégia sem mediação de internet para as atividades escolares.

$\checkmark \quad 89 \%$ das redes e sistemas nesse período não tinham data prevista para retorno ao ensino presencial.

$\checkmark$ Apenas 23\% das redes municipais iniciaram ou concluíram seus protocolos de retorno das aulas presenciais.

$\checkmark \quad 44 \%$ das redes estão desenvolvendo ou já têm planos de comunicação para a comunidade.

$\checkmark \quad 11 \%$ das redes tem previsão de retorno às aulas presenciais.

Esses números evidenciam que passados cinco meses de suspensão das aulas presenciais, as redes e sistemas de ensino ainda enfrentavam adversidades na condução do processo educacional. Também mostram que é grande o percentual de estudantes sem aulas de fato e a maioria tem recebido apenas material impresso, comprometendo as aprendizagens e quase ausente a interação entre professores e estudantes.

O planejamento, essencial para condução da gestão da educação, é extremamente necessário para a tomada de decisões, no entanto, tem sido pouco implementado, podendo comprometer ainda mais as aprendizagens dos estudantes, provocar abandono e retrocessos ao processo educacional.

Em relação à terceira pesquisa da Undime, Itaú e Unicef (2021), realizada entre os dias 29 de janeiro a 21 de fevereiro de 2021 e teve por objetivo saber sobre a volta às aulas, como foi o ano letivo em 2020 e o planejamento para o ano letivo 2021. O estudo em questão revelou que $70 \%$ das redes concluíram o ano letivo de 2020, até o mês de dezembro; 23\% reorganizaram para conclusão em 2021 e 7\% estava em processo de reorganização do calendário para 2021.

Nessa pesquisa, também foram observadas as seguintes situações:

Das redes que cumpriram o calendário escolar, em 2020, 92\% fez apenas com atividades não presenciais e 8\% desenvolveu o ensino híbrido.

A pesquisa revelou que nos municípios que é sistema de ensino, a maioria teve a participação dos conselhos municipais de educação na reorganização do calendário escolar e publicou normativas.

A atividade pedagógica não presencial mais utilizada, em 2021, foi material impresso de acordo 99\% dos municípios, seguido de orientações pelo WhatsApp, desenvolvidas por 92,5\%.

A participação dos alunos nas atividades remotas foi acima de $75 \%$. 
Em relação ao planejamento para ano letivo de 2021, a grande maioria das redes e sistemas pretende voltar de forma remota, cerca de 77,7\% dos 135 que responderam à pesquisa. Apenas 5\% desse total se planejaram para iniciar as aulas de forma presencial e 11\%, de forma híbrida.

A pesquisa também identificou que a maioria, ou seja, 102 redes e/ou sistemas, não seguiu o calendário da Secretaria de Estado da Educação.

No que se refere à formação dos professores, gestores e demais trabalhadores em educação:

$\checkmark \quad 50,4 \%$ dos municípios ofereceram em 2020 e planeja oferecer em 2021;

$\checkmark \quad 41,4 \%$ não ofereceram em 2020, mas planeja oferecer em 2021;

$5,2 \%$ não ofereceram em 2020 e não planejou para 2021 e,

$3 \%$ ofereceram em 2020, sem previsão de oferecer em 2021.

Quanto aos protocolos de segurança para a volta às aulas, a pesquisa relevou que a maioria está em processo de construção, sendo que, dos 135 que responderam, 94 municípios estão em processo de construção, 25 concluíram e 16 nem iniciaram.

As maiores dificuldades apontadas pelos municípios, neste momento da pandemia, foram o acesso dos estudantes à Internet, a adequação da infraestrutura das escolas públicas municipais, o planejamento pedagógico para o currículo continuum e o ensino híbrido.

Os dados apresentados evidenciam dificuldades nas mudanças do processo educacional especialmente relacionadas à utilização das tecnologias e à infraestrutura necessária para se garantir uma oferta de qualidade que atenda a todos os alunos. A estratégia mais utilizada de material impresso levanta várias incógnitas se esta, de fato, propiciou aprendizado; se os alunos conseguiram desenvolver habilidades mínimas; se causou desmotivação, enfim, são muitos dilemas que trarão repercussões negativas para a vida escolar da grande maioria dos estudantes das escolas públicas municipais do Estado do Tocantins. Essas são reflexões que a pandemia trouxe e uma delas refere-se ao avanço tecnológico e ao fato de que é preciso repensar o papel do professor e a necessidade de implementar estratégias para tornar a escola mais útil e eficaz aos alunos (Cunha Junior, et al., 2020).

Um aspecto que a pesquisa também mostrou foi a atuação significativa dos conselhos municipais de educação no processo de reorganização do calendário e participação no planejamento dos sistemas para que as atividades escolares fossem desenvolvidas. 
O modelo híbrido que combina variadas formas de aprendizagem no ambiente virtual e presencial ainda tem sido pouco utilizado, vez que a dificuldade de acesso à internet ainda é grande. A dificuldade de adaptação dos professores ao ambiente virtual, bem como a falta de infraestrutura adequada das escolas contribuem para que se trabalhe mais com a estratégia de material impresso, mostram-se insuficientes à garantia das aprendizagens.

A quarta pesquisa-análise da Undime, Itaú e Unicef (2021), sobre a educação na pandemia da Covid-19 foi realizada entre os dias 15 de junho e 09 de julho de 2021 e buscou coletar dados sobre como as secretarias estavam se preparando para o ano letivo 2021. Essa pesquisa foi respondida por 95\% das redes e/ou sistemas municipais de educação, sendo que a maior parte das respostas foram dadas pelos dirigentes municipais de educação.

A pesquisa, então, apurou sobre a transição dos anos letivos de 2020 e 2021; as estratégias de ensino não presencial adotadas, em 2020; o planejamento do segundo semestre de 2021; e os principais desafios das secretarias municipais de educação, naquele momento.

Quanto ao início das aulas, em 2021, o estudo apontou que dos 132 municípios que responderam à pesquisa, 123 iniciaram as aulas de forma não presencial, 7 de forma híbrida e apenas 2 de forma presencial.

O retorno das aulas contemplou todos os alunos dos anos iniciais do ensino fundamental e quase todos da educação infantil, ou seja, 99,2\% dos municípios que responderam à pesquisa. Em relação à participação dos Conselhos Municipais de Educação, ficou evidente que a maioria dos municípios teve apoio dos conselhos para a reorganização do calendário de 2021.

Quanto às estratégias de ensino para o ano letivo 2021, a pesquisa mostrou a continuidade da utilização dos mesmos métodos adotados em 2020, sendo o material impresso e as orientações pelo WhatsApp as técnicas mais usadas.

Para a integração curricular entre os anos 2020 e 2021, 113 municípios declararam adotar estratégias a esse respeito. A principal estratégia utilizada pelas secretarias municipais de educação para acompanhar e monitorar as atividades pedagógicas não presenciais consiste no diálogo com diretores e coordenadores, seguido de avaliações internas, conversas regulares com professores, indicadores e metas para verificar o acompanhamento das atividades, bem como reunião com pais ou responsáveis, tendo em vista o 
acompanhamento do processo de aprendizagem.

A pesquisa também mostrou que 115 dos 132 municípios que responderam, afirmaram que não devem seguir o calendário estadual. No que se refere à construção dos protocolos sanitários, 72 municípios já concluíram seus respectivos protocolos e 58 estão em processo de construção.

Os desafios que têm se destacado, nesse processo, dizem respeito ao apoio pedagógico e suporte aos diretores, à busca ativa escolar, a conectividade de estudantes e a infraestrutura das escolas, consideradas, portanto, as maiores dificuldades para o cumprimento do calendário escolar 2021.

\section{Atuação da Undime para apoiar os municípios}

A Undime, por meio das provocações, questionamentos e diálogos com os dirigentes municipais de educação, articulou a criação da Rede ColaborAção Tocantins (RCT), tendo em vista contribuir e apoiar as respectivas redes e os sistemas municipais como define o objetivo da proposta:

Apoiar as redes e os sistemas municipais de educação/ensino do Estado do Tocantins no enfrentamento da crise educacional derivada da pandemia da COVID-19, notadamente, na sistematização da oferta educacional no período da pandemia e no processo de retomada das atividades educacionais (Rede Colaboração Tocantins, 2020, p. 7).

A RCT se formou com representantes de instituições que se sensibilizaram como responsáveis pela garantia da educação às crianças e estudantes das escolas públicas dos 139 municípios do Estado do Tocantins. Tratase de uma corrente que agrega as seguintes instituições: União dos Dirigentes Municipais de Educação Seccional Tocantins, Ministério Público Estadual, Universidade Federal do Tocantins e Associação Tocantinense de Municípios.

É papel da RCT contribuir para garantir o acesso ao ensino, aos estudantes, durante o período de isolamento social, com orientações pautadas no meio social, em seus tempos e espaços de convívio, por meio de atividades híbridas. Considerando a complexidade do formato hibrido e remoto, houve a necessidade de propor atividades pedagógicas mediadas por tecnologias ou material impresso e adequar o currículo existente com possibilidade de incorporar novos conceitos teóricos.

Com o apoio da Undime e Ministério Público, iniciou-se, em agosto de 2020, o diagnóstico para levantamento da situação de todas as redes e sistemas/educação. Após sinalização de interesse da parte dos municípios, houve assinatura de um termo de adesão como forma de garantir a 
autonomia e a liberdade de decisão, tendose a confirmação da participação de 136 municípios. Com as informações adquiridas, estabeleceram-se os conteúdos a serem desenvolvidos, o formato do diálogo, a construção dos indicadores, as dúvidas e inseguranças.

A Rede se organizou com especialistas de currículo das distintas áreas de conhecimento para construir uma proposta de trabalho única para todas as redes e sistemas/educação tendo como referências a Base Nacional Comum Curricular (BNCC) e o Documento Curricular do Tocantins (DCT), bem como a escuta de educadores e pesquisadores brasileiros do campo da formação docente. A equipe foi organizada da seguinte forma (Rede Colaboração Tocantins, 2020):

$\checkmark \quad$ Comissão de Gestão da Crise define a direção de todo o processo de atuação da rede;

$\checkmark \quad$ Coordenador Geral - coordena todo o trabalho administrativo;

$\checkmark \quad$ Técnicos de Apoio à Formação - garantem os trabalhos administrativos;

$\checkmark \quad$ Coordenador de Apoio aos Sistema/Educação - coordena o grupo de apoio às redes;

$\checkmark$ Coordenador Regional coordenação dos trabalhos no âmbito do município;

$\checkmark \quad$ Formador - organiza a ementa;

$\checkmark \quad$ Orientador Municipal - orienta os professores e equipe técnica;

$\checkmark \quad$ Monitores de Formação acompanha os trabalhos no âmbito da Secretaria de Educação;

$\checkmark$ Supervisor Municipal acompanha o cumprimento das ações;

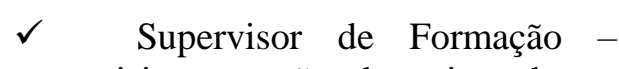
supervisiona as ações dos orientadores.

A estrutura de pessoal foi pensada com base nos parâmetros de outros programas federais dos quais a UndimeTO foi colaboradora na execução. Quanto ao organograma, este assenta-se na concepção da gestão democrática, sendo as decisões tomadas sob a coordenação da Comissão de Gestão, em diálogo com os dirigentes municipais, os especialistas, os formadores e os demais colaboradores.

Sendo a Undime uma instituição que atua diretamente com a educação dos municípios visando apoiar e defender a educação como direito a ser garantido, a estrutura de pessoal foi organizada a partir da concepção da gestão democrática, envolvendo os dirigentes municipais de educação e especialistas, sendo que a maioria dos profissionais indicados possuem experiências de trabalho com a educação municipal.

A proposta de atendimento aos municípios foi organizada em dois blocos de formação, sendo o bloco I direcionado para gestores e o bloco III voltado para professores e coordenadores pedagógicos, envolvendo os seguintes aspectos (Rede Colaboração Tocantins, 2020):

1. Enfrentamento dos desafios da gestão da crise; 
2. Implantação de uma Rede de apoio neste período permanente e pós pandêmicos;

3. Atendimento de orientação pedagógica destinado à formação de equipe para fortalecer os sistemas de educação/ensino.

O projeto iniciou com os gestores, com apoio centrado na garantia da preservação da vida das crianças, estudantes e professores e, posteriormente, com os desafios relacionados à garantia da oferta de ensino. As ações objetivaram assegurar a inclusão dos estudantes com maiores dificuldades de acesso às atividades de ensino em virtude das situações de vulnerabilidade socioeconômica vivenciadas, assim como garantir a segurança dos profissionais que fazem parte do grupo de risco, ainda sem acesso a vacina.

Portanto, a formação dos professores foi pensada de forma a construir um currículo para o período pandêmico, em que as aprendizagens tivessem o menor impacto na vida das crianças e estudantes.

\section{Notas conclusivas}

Observou-se que a pandemia da Covid-19 provocou mudanças no processo educacional. Ficou evidente que para se garantir a educação, nesse período, foi necessária a utilização de diversos meios tecnológicos e o estabelecimento de um novo formato de ensino não presencial, remoto e híbrido. Tais medidas foram fundamentais para que as aulas e o processo educacional continuassem sendo ofertados, a despeito das várias dificuldades enfrentadas, como o conjunto de pesquisas realizadas pela Undime demonstrou.

As dificuldades de utilização das tecnologias em razão da insuficiência ou falta de conectividade, assim como a falta de computadores ou notebooks, as dificuldades das escolas e dos professores quanto ao uso das ferramentas e instrumentos tecnológicos, como, também, das redes na realização das formações continuadas para atender essa nova realidade foram desafios que se impuseram aos municípios.

Os resultados das pesquisas aqui apresentadas evidenciaram as fragilidades das Secretarias Municipais de Educação na tomada de decisões acerca do ensino durante a pandemia da Covid-19. Também ficou evidenciado que em pleno século XXI o acesso à Internet de alta velocidade ainda não é uma realidade para a maioria das famílias e estudantes dos municípios pesquisados, fazendo com que o método de ensino mais utilizado continuasse sendo o material impresso.

A Rede Colaboração Tocantins tem realizado um trabalho de impacto importante junto às redes/ sistemas de 
educação nos municípios, voltado para a atuação da gestão e do trabalho pedagógico com os professores, coordenadores e técnicos. Há necessidade de continuidade desse apoio para que se possa concluir o percurso traçado, o que se constitui um grande desafio.

A realidade apresentada reverbera diversas necessidades: de melhor compreensão da legislação e das normas educacionais, de maiores investimentos em tecnologia e conectividade no âmbito das escolas, da formação dos profissionais da educação e de melhorias na infraestrutura das unidades educacionais para que seja ofertada educação de qualidade e se cumpra o direito à educação.

\section{Referências}

Arruda, E. P. (2020). Educação remota emergencial: elementos para políticas públicas na educação brasileira em tempos de Covid-19. Em Rede, 7(1), 257-275. Recuperado de: Recuperado de: https://www.aunirede.org.br/revista/index. php/emrede/article/view/621

Bacich, L. (2016). Ensino híbrido: proposta de formação de professores para uso integrado das tecnologias digitais nas ações de ensino e aprendizagem. In Anais do Workshop de Informática na escola (pp. 679).

https://doi.org/10.5753/cbie.wie.2016.679

Bacich, L. (2018). Inovação na educação. Especial da Geekie sobre ensino híbrido. Recuperado de: https://lilianbacich.com/2018/02/11/especi al-da-geekie-sobre-ensino-hibrido
Barreto, J. S., Amorim, M. R. O. R., \& Cunha C. (2020). A Pandemia da Covid-19 e os Impactos na Educação. Revista JRG de Estudos Acadêmicos, 3(7), 792-805. Recuperado de: https://www.revistas.uneb.br/index.php/en cantar/article/view /8480

Bazzo, V. L. (2020). PNE e o direito à educação em tempos de pandemia. In Dourado, L. F. (Org.). PNE, políticas e gestão da educação: novas formas de organização e privatização - Anpae. (pp. 35-51). Brasília - DF.

Brasil. (1988). Constituição da República Federativa do Brasil. Senado Federal. Brasília - DF.

Brasil. (2014). Lei $n^{o}$ 13.005, de 25 de junho de 2014. Aprova o Plano Nacional de Educação - PNE, e dá outras providências. Presidência da República. Brasília - DF. Recuperado de: http://www.planalto.gov.br/ccivil_03/_ato2 011-2014/2014/lei/113005.htm.

Brasil. (2020). Instituto Brasileiro de Geografia e Estatística - IBGE. Pesquisa Nacional por Amostra de Domicílios. Instituto Brasileiro de Geografia e Estatística - IBGE. Rio de Janeiro. Recuperado de: https://biblioteca.ibge.gov.br/visualizacao/l ivros/liv101778.pdf.

Brasil. (2020a). Conselho Nacional de Educação. Parecer CNE/CP $n^{\circ}$ 5/2020. Reorganização do Calendário Escolar e da possibilidade de cômputo de atividades não presenciais para fins de cumprimento da carga horária mínima anual, em razão da Pandemia da COVID-19. Brasília - DF.

Brasil. (2020b). Conselho Nacional de Educação. Parecer CNE/CP $n^{\circ}$ 11/2020. Orientações Educacionais para a Realização de Aulas e Atividades Pedagógicas Presenciais e Não 
Presenciais no contexto da Pandemia. Brasília - DF.

Brasil. (2020c). Lei $n^{\circ}$ 14.040, de 18 de agosto de 2020. Estabelece normas educacionais excepcionais a serem adotadas durante o estado de calamidade pública .... Diário Oficial da União: seção 1, n. 159, 19 ago. Brasília - DF.

Brasil. (2020d). Lei $n^{\circ}$ 14.040, de 18 de agosto de 2020. Estabelece normas educacionais excepcionais a serem adotadas durante o estado de calamidade pública. Presidência da República. Brasília - DF. Recuperado de: https://www.in.gov.br/en/web/dou/-/lei-n14.040de-18-de-agosto-de-2020272981525 .

Brasil. (2020e). Conselho Nacional de Educação. Resolução CNE/CP n 2/2020. Institui Diretrizes Nacionais orientadoras para a implementação dos dispositivos da Lei ${ }^{\circ} 14.040$, de 18 de agosto de 2020. Diário Oficial da União: n. 237, seção 1. Brasília, DF.

Brasil. (1996). Lei $n^{o}$ 9.394, de 20 de dezembro de 1996. Estabelece as diretrizes e bases da educação nacional. Diário Oficial [da] República Federativa do Brasil, Poder Executivo, Brasília-DF.

Candau, V. M. (2012). Diferenças Culturais, Interculturalidades e Educação em Direitos Humanos. Educ. Soc., 33(118), 235-250. https://doi.org/10.1590/S0101$\underline{73302012000100015}$

Cunha Junior, A. S. et al. (2020). Educação de jovens e adultos (EJA) no contexto da pandemia de COVID-19: cenários e dilemas em municípios baianos. Revista Encantar - Educação, Cultura e Sociedade, 2, 01-22.

Cury, C. R. J. (2002). Direito à educação: direito à igualdade, direito à diferença.
Cadernos de Pesquisa, 116, 245-262. https://doi.org/10.1590/S0100$\underline{15742002000200010}$

Furtado, J. C. F. (2021). Ensino Remoto, Ensino Híbrido e a reinvenção do Professor.

https://www.profissionaissa.com/palestra/e nsino-remoto-ensino-hibrido-e-areinvencao-do professor

Gil, A. C. (2008). Como elaborar projetos de pesquisa. São Paulo, Atlas.

Grossi, M. G. R. (2020). O ensino remoto é uma modalidade de educação. Recuperado de: https://avacefetmg.org.br.

Lagares, R. (2020). (Org.). Rede Colaboração Tocantins. Caderno Educação Municipal - Gestão da Educação: validação das ações administrativas e pedagógico-curriculares e finalização do ano letivo de 2020. Palmas - TO.

Lima, T. C. S., \& Mioto, R. C. T. (2007). Procedimentos metodológicos na construção do conhecimento científico: a pesquisa bibliográfica. Rev. Katálysis, 10(N.esp). 37-45,

https://doi.org/10.1590/S141449802007000300004.

Nóvoa, A. (1997). (Org.). Os professores e sua formação. Lisboa: Dom Quixote.

Oliveira, J. S. G., \& Peres, S. da M. D. (2020). Análise jurídica do Parecer CNE/CP $n^{\circ}$. Publica Gestão Educacional do escritório Graboski Advogados Associados. Material impresso.

OPAS/OMS. (2020). Folha informativa COVID-19 (doença causada pelo novo coronavírus.

[S.1].Recuperado: https://www.paho.org/br a/index.php?option $=$ com_content $\&$ view $=\mathrm{a}$ rticle\&id=6101: covid19\&Itemid=875. 
Rede Colaboração Tocantins. (2020). Rede Colaboração Tocantins Caderno 2. Gestão da educação na conjuntura da pandemia: Com a palavra, cursistas e formadores. Palmas/TO.

Rede Colaboração Tocantins. (2020). Rede Colaboração Tocantins. Caderno 1. Gestão da Educação: validação das ações administrativas e pedagógico-curriculares e finalização do ano letivo de 2020. Undime. Palmas-TO.

Rede Colaboração Tocantins. (2021). Rede Colaboração Tocantins. Caderno 3. Gestão das redes e dos sistemas educacionais: afirmação dos direitos à vida e a educação no retorno às atividades escolares em 2021. Undime. Palmas - TO.

Tocantins. (2020). Decreto Estadual $n^{o}$ 6.065, de 13 de março de 2020. Determina ação preventiva para o enfrentamento do COVID-19 - novo Coronavírus. Palácio do Governo. Palmas - TO. Recuperado de: http://servicos.casacivil.to.gov.br/decretos/ decreto/6064.

Tocantins. (2020a). Decreto $n^{\circ}$ 6.064, de 12 de março de 2020. Instala o Comitê de Crise para a Prevenção, Monitoramento e Controle do Vírus Covid-19 - novo Coronavírus. Palácio do Governo. Palmas - TO. Recuperado de: http://servicos.casacivil.to.gov.br/decretos/ decreto/6064.

Tocantins. (2020b). Decreto $n^{\circ} 6.071$, de 18 de março de 2020. Determina ação preventiva para o enfretamento da pandemia da Covid-19 (novo Coronavírus). Palácio do Governo. Palmas - TO. Recuperado de: http://servicos.casacivil.to.gov.br/decretos/ decreto/6071.

Tocantins. (2020c). Decreto $n^{\circ}$ 6.073, de março de 2020. Determina antecipação das férias escolares na Rede Pública Estadual de Ensino, e adota outras providências.
Palácio do Governo. Palmas - TO. Recuperado de: http://servicos.casacivil.to.gov.br/decretos /decreto/6073.

Tocantins. (2020e). Ofício Circular $n^{\circ}$ 02, de 12 de maio de 2020. O Conselheiro do Tribunal de Contas do Tocantins, o Senhor André Luiz de Matos Gonçalves, determina que os Municípios elaborem em até 15 dias o plano para implantação do ensino remoto na educação básica e que o novo formato de ensino seja implantado em até 30 dias. Tribunal de Contas do Tocantins, Palmas - TO.

Tocantins. (2020f). Resolução CEE/TO n ${ }^{\circ}$ 105, de 08 de abril de 2020. Estabelece formas de reorganização do Calendário Escolar/ 2020 e define o regime especial de atividades escolares não presenciais no Sistema Estadual de Ensino do Tocantins, para fins de cumprimento do ano letivo de 2020, como medida de prevenção e combate ao contágio do Novo Coronavírus (COVID-19). Diário Oficial do Estado: Palmas, ano 32, n. 5.582, p. 7-9, 15 abr. 2020f. Disponível em: https://central3.to.gov.br/arquivo/501542/. Acesso em: 4 nov. 2020.

Tocantins. (2020g). Resolução CEE/TO $n^{\circ}$ 154, de 17 de junho de 2020. Estabelece normas complementares para a reorganização do Calendário Escolar, os planejamentos e práticas pedagógicas para a oferta e o cômputo de atividades educacionais não presenciais, para fins de cumprimento da carga horária mínima anual, com o objetivo de minimizar o impacto decorrente da Pandemia da COVID-19, na educação. Conselho Estadual de Educação do Tocantins. Palmas - TO. Recuperado de: https://central.to.gov.br/download/19878. Undime, Itaú \&Unicef. (2020). Desafios das Secretarias Municipais de Educação na oferta das atividades não presenciais. Relatório Brasil: Undime; Consed. Recuperado de: 
https://undime.org.br/uploads/documentos/ php7UsIEg_5ee8efcba8c7e.pdf

Undime, Itaú \& Unicef (2021). Pesquisa Undime Educação na Pandemia. Recuperado de: https://www.unicef.org/brazil/media/15181 /file/pesquisa-undime-educacao-napandemia-quinta-onda.pdf

Vieira, M. F., \& Seco, C. (2020). A Educação no contexto da pandemia de COVID-19: uma revisão sistemática de literatura. Brazilian Journal of Computers in Education. Revista Brasileira de Informática na Educação - RBIE, 28, 1013-1031.

https://doi.org/10.5753/rbie.2020.28.0.101 $\underline{3}$

i Fonte: Centro de Informações Estratégicas de Vigilância em Saúde / SES-TO. Recuperado de: http://coronavirus.to.gov.br.

\section{Informações do Artigo / Article Information}

Recebido em : 02/11/2021

Aprovado em: 04/12/2021

Publicado em: 19/12/2021

Received on November 02nd, 2021

Accepted on December 04th, 2021

Published on December, 19th, 2021

Contribuições no Artigo: Os(as) autores(as) foram os(as) responsáveis por todas as etapas e resultados da pesquisa, a saber: elaboração, análise e interpretação dos dados; escrita e revisão do conteúdo do manuscrito e; aprovação da versão final publicada.

Author Contributions: The author were responsible for the designing, delineating, analyzing and interpreting the data, production of the manuscript, critical revision of the content and approval of the final version published.

Conflitos de Interesse: Os(as) autores(as) declararam não haver nenhum conflito de interesse referente a este artigo.

Conflict of Interest: None reported.

Avaliação do artigo

Artigo avaliado por pares.

Article Peer Review

Double review.

Agência de Fomento

Não tem.

Funding

No funding.

Como citar este artigo / How to cite this article

APA

Rodrigues, R. S., Vizolli, I., Sousa, M. S. R., \& Silva, M. L. A. (2021). Gestão da educação municipal nos sistemas e redes de ensino/educação tocantinenses: desafios na garantia do direito educacional no período da pandemia. Rev. Bras. Educ. Camp., 6, e13332. http://dx.doi.org/10.20873/uft.rbec.e13332

ABNT

RODRIGUES, R. S.; VIZOLLI, I.; SOUSA, M. S. R.; SILVA, M. L. A. Gestão da educação municipal nos sistemas e redes de ensino/educação tocantinenses: desafios na garantia do direito educacional no período da pandemia. 6 , e13332, 2021. http://dx.doi.org/10.20873/uft.rbec.e13332 